\title{
Agrochemicals and the Ghanaian Environment, a Review
}

\author{
Joseph R. Fianko ${ }^{1,4}$, Augustine Donkor ${ }^{2}$, Samuel T. Lowor ${ }^{3}$, Philip O. Yeboah ${ }^{4}$ \\ ${ }^{1}$ Department of Chemistry, NNRI/GAEC, Legon, Accra; ${ }^{2}$ Department of Chemistry, University of Ghana, Legon, Accra; ${ }^{3}$ Cocoa \\ Research Institute of Ghana, Akim Tafo; ${ }^{4}$ School of Nuclear and Allied Sciences, University of Ghana, Legon, Accra. \\ Email: jrfianko@yahoo.com
}

Received August 18 $8^{\text {th }}, 2010$; revised Janaury $17^{\text {th }}, 2011$; accepted February $22^{\text {nd }}, 2011$.

\begin{abstract}
Agrochemicals are generally recognized as a significant factor in enhancing the ability to meet Ghana's need for sufficient, safe and affordable food and fiber, however, increased usage have led to environmental deterioration. In Ghana agriculture and public health sectors remain the major contributors of pollutants into the environment. This is a systematic review of studies done in Ghana to give an integrated picture of agrochemicals especially pesticides exposure to humans, animals, plants, water, soil/sediment and atmosphere in Ghana. Although the widespread usage of agrochemicals in Ghana has contributed immensely to increased food supply and improvement in public health, it has caused tremendous harm to the environment. Water bodies, fish, vegetables, food, soil and sediment have been found to be pesticide contaminated. There is considerable evidence that farmers have overused agrochemicals especially pesticides. It is evident from biological monitoring studies that farmers are at higher risk for acute and chronic health effects associated with pesticides due to occupational exposure. Furthermore the intensive use of pesticides involves a special risk of for field workers, consumers and unacceptable residue levels in exportable products may serve as barrier to international trade. This review will set the future course of action of different studies on agrochemical usage and pesticide exposure in Ghana.
\end{abstract}

Keywords: Ghana, Agrochemicals, Environment, Pollution, Exposure

\section{Introduction}

Agrochemicals are integral part of current agriculture production systems around the world. Accordingly, the use of agrochemicals viz fertilizers and pesticides remain a common practice particularly in many nations in the tropical world [1]. Pesticides like 1,1,1-trichloro-2,2-bis (4-chlorophenyl) ethane (DDT) and 1,2,3,4,5,6-hexachlorocyclohexane $(\mathrm{HCH})$ which are environmentally persistent prohibited from use in developed nations continue to be most widely used pesticides in developing countries including Ghana because they are cheap, easy to synthesis or they are given by developed nations. Many pressure groups, example, Consumer Associations, Non-governmental Organizations and International bodies are against the presence of these persistent pesticides in the environment. They perceive the presence of pesticide residues in the environment as detrimental to human health and water quality.

The contamination of the environment and exposure of the public to pesticide residues in food could lead to high health risk. Results of scientific research reveal that even in low concentrations, the combined effect of persistent synthetic chemicals such as pesticides causes suppression of immune response and hypersensitivity to chemical agents. Causes of breast cancer, reduced sperm count, male sterility etc are well documented as a result of pesticide ingestion [1]. Death cases and pesticide poisoning have been reported around the world particularly in developing countries [2]. In Ghana, agrochemicals used in farming dates back to the colonial era and have been inherent component in agricultural practices in the nation. The objective of this review is to summarize the agrochemical monitoring studies in Ghana and gives the true picture of their detrimental effects to the environment. It will also determine the current state of knowledge in agrochemicals in Ghana to set the future plan of action in agrochemical research in Ghana.

\section{Agro-Chemical Use in Crops in Ghana}

Agriculture is the most important sector in Ghana's economy, forming nearly $41 \%$ of total Gross Domestic Product (GDP) [3]. Out of the total area of 238.854 
square kilometers of Ghana only 57\% (13 628000 hectares) is suitable for agriculture. However, 6331000 hectares of the arable land are cultivated because the soils are infertile and only productive with proper management and good agricultural practice $[4,5]$. In the light of these and the need to increase food supply, the use of crop protection chemicals, organic fertilizers, improved water and soil management as well as increased area of agriculture land seems the simplest way to obtain better yield. Instead, the current trend has been the decrease of agriculture land (hectares per inhabitant) in all regions of the globe as a result of population growth, net loss of agricultural land due to erosion, reduction of fertility, salinization and desertification of soils [1]. Therefore the best response to the need for increasing food production is more intensive use of agrochemicals.

As farms have become massive in size, the challenges in keeping the crop free of damage have increased. Hand-tilling weeds have become impractical, as one example. Thus the whole world has known a continuous growth of agrochemical usage both in numbers and quantities. The use of agrochemicals has been critically important in increasing the yield of agricultural crops. However, some uses of agrochemicals cause environmental and ecological damage, which detracts significantly from the benefits gained by the use of these materials. The most commonly used fertilizers are inorganic compounds of nitrogen $(\mathrm{N})$, Phosphorus $(\mathrm{P})$ and potas$\operatorname{sium}(\mathrm{K})$.

In Ghana, agro-chemicals are used in cocoa, oil palm, cola nut, coffee and cotton farms, vegetable (e.g. tomato, eggplant, onion, pepper, okra, cabbage, lettuce, carrot) and fruit production (e.g. papaya, citrus, avocado, mango, cashew, pineapple), mixed-crop farming systems involving cereals (e.g. maize, millet, sorghum, rice), tuber crops (e.g. yam, cassava, cocoyam, sweet potato) and legumes (e.g. cowpea, bambara nut, groundnut, soybean). Overall, agrochemical especially fertilizer use on pineapple is fairly high because pineapple is grown on sandy soils.

\section{Fertilizer Use in Ghana}

The use of chemical fertilizers has increased tremendously worldwide since the 1960s and is largely responsible for the green "revolution" i.e. the massive increase in production obtained from the same surface of land with the help of mineral fertilizers (nitrogen, phosphorus, potassium) and intensive irrigation [1]. At present, Ghana does not manufactured fertilizers; all fertilizers used in Ghana are imported [1]. The major importers of fertilizers into Ghana are private companies, Agricultural Development Bank and some commercial farms. The most important imported products are compound fertilizers Ammonium Sulphate (AS) and Muriate of Potash (MOP) with urea, Single Super Phosphate (SSP) and Triple Super Phosphate (TSP) being minor imports (Table 1) [3].

Compound fertilizers accounted for 48 percent of the total amount of fertilizers consumed in Ghana between 1995 and 2003 with nitrogenous fertilizers (urea and ammonium sulphate) accounting for 30 percent of the total fertilizers consumed. The consumption of fertilizers fell substantially in the early 1980s because of adverse economic conditions; nonetheless, it increased in the second half of the 1990s following an improvement in the national economy, ever since it has been steady (Table 2). The Upper East and the Upper West Regions are

Table 1. Fertilizer imports into Ghana ("000 tonnes").

\begin{tabular}{cccccccc}
\hline Year & N.P.K (15-15-15) & Other Compounds & Urea & MOP & AS & SSP/TSP \& others & Total \\
\hline 1997 & 19.2 & 17.9 & 1.9 & 5.5 & 10.7 & 1.1 \\
1998 & 13.1 & 8.8 & 0.5 & 3.1 & 13.3 & 3.3 \\
1999 & 3.2 & 0.4 & 0 & 8.1 & 4.8 & 42.4 \\
2000 & 14.1 & 0.8 & 0.1 & 4.5 & 23.2 & 2.5 \\
2001 & 31.8 & 17.5 & 2.5 & 4.1 & 22.6 & 0.8 \\
\hline
\end{tabular}

Table 2. Mean fertilizer consumption by region in Ghana.

\begin{tabular}{|c|c|c|c|c|c|}
\hline \multirow{2}{*}{ Region } & 1997 & 1998 & 1999 & 2000 & 2001 \\
\hline & \multicolumn{5}{|c|}{ (tonnes) } \\
\hline Ashanti & 5167 & 3893 & 2023 & 4046 & 7438 \\
\hline Brong Ahafo & 7582 & 5712 & 2969 & 5937 & 10,914 \\
\hline Central & 1629 & 1229 & 638 & 1275 & 2345 \\
\hline Eastern & 1011 & 762 & 396 & 792 & 1455 \\
\hline Greater Accra & 1236 & 931 & 484 & 967 & 1779 \\
\hline Northern & 15,220 & 11,467 & 5960 & 11,917 & 21,910 \\
\hline Volta & 8481 & 6390 & 3321 & 6640 & 12,208 \\
\hline Western & 337 & 254 & 132 & 264 & 483 \\
\hline Total & 56,164 & 42,317 & 16,593 & 43,975 & 80,846 \\
\hline
\end{tabular}

Source: $[4,5]$ 
the largest fertilizer consumers in Ghana. The Upper East Region has two large irrigation schemes at Tono and Vea. Because of the high economic value of tomatoes and onions during the dry season, farmers regularly tend to apply more fertilizers to these crops, hence the increased volume of fertilizers usage in the Northern sector.

Pesticide Use in Ghana: Ghana is a developing country experiencing high economic growth rate in the West African Sub-region [3]. As an agriculture-based nation, the use of pesticides contributes much to the national development and public health programmes. Ever since the inception of pesticides, its use to protect crops from pests has significantly reduced losses and improved the yield of crops such as cereals, vegetables, fruits and other crops. Ghana thus, has known a continuous growth of pesticide usage, both in number of chemicals and quantities because of the expansion of area under cultivation for food, vegetables and cash crops [4].

Pesticide application in Ghana is more concentrated in cocoa, oil palm, cereals, vegetables and fruits sectors. Although purchased physical inputs (agrochemicals, seeds and tools) represent less than $30 \%$ of the total cost of crop production, the use of pesticides is becoming more widespread. For instance, between 1995 and 2000, about 21 different kinds of pesticides were imported into the country for agricultural purposes [5]. Its use has been embraced by local communities that are making a living from sale of vegetables and other cash crops. There is ample evidence that this products especially tomatoes are always sprayed and sold immediately after maturity for consumption. This inevitably puts a high risk on consumers who always get their supply directly from the farmers. In Ghana, it is estimated that $87 \%$ of farmers who use pesticides, apply any of the following or a combination of pyrethroids, organophosphates, carbamates, organochlorines on vegetables [6].

Among the different types of pesticides known, organochlorine pesticides are the most popular and extensively used by farmers due to their cost effectiveness and broad spectrum activity. Lindane was widely used in Ghana on cocoa plantations, vegetable farms, and for the control of stem borers in maize [7]. Endosulfan is popularly applied in cotton growing areas, vegetables farms, and coffee plantations [5] in some parts Ghana. Pesticides particularly DDT and lindane which are no longer registered for any use in the country were once employed to control ecto-parasites of farm animals and pets in Ghana [8].

Pesticides mostly used to control foliar pests of pineapple in Ghana include chlorpyrifos, dimethoate, diazinon, cymethoate and fenitrothion while the fungicides maneb, carbendazim, imazil, copper hydroxide are used for post-harvest treatment $[9,10]$. Lambda-cyhalothrin, cypermethrin, dimethoate and endosulfan are also used by vegetable growers in tomato, pepper, okra, egg-plant, cabbage and lettuce farms. Glyphosate, fluazifop-butyl, ametryne, diuron or bromacil are normally employed in land clearing [11]. Nonetheless, the most extensively used pesticides in the pepper, tomato, groundnut and beans cultivation are karate, cymbush, thiodine, diathane, lubillite and kocide [12].

Dinham [13] estimates that $87 \%$ of farmers in Ghana use chemical pesticides to control pests and diseases on vegetables and fruits. Ntow et al. [8] gave the proportions of pesticides used popularly on vegetable farms as herbicides (44\%), fungicides $(23 \%)$ and insecticides $(33 \%)$. In a study encompassing 30 organized farms and 110 kraals distributed throughout the 10 regions of Ghana, Awumbila and Bokuma [14] found that 20 different pesticides were in use with the organochlorine lindane being the most widely distributed and used pesticides, accounting for $35 \%$ of those applied on farms. Of the 20 pesticides, $45 \%$ were organophosphorous, $30 \%$ were pyrethroids, $15 \%$ were carbamates and $10 \%$ were organochlorines [14].

In the public health sector, pesticides, primarily temephos have been used by the Onchocerciasis Programme in the Volta Basin for the control of black flies (Simulium spp. Diptera: Simulidae), which transmit Onchecerciasis (African river blindness, a disease caused by the pathogenic nematode, Onchocerca volvulus) to humans and for the control of diseases [15] and domestic pests, such as cockroaches, various flies, mosquitoes, ecto-parasites including ticks and other insects [16]. Pesticides have also been used to control black flies along the banks of the Tano and Pra rivers [17].

Analysis of pesticide trade flow patterns, recorded by Ghana's Statistical Service, in 1993 indicated that a total of $3,854,126 \mathrm{~kg}$ of pesticides were imported with the following distribution and use as per Figure 1 [18]. Besides, a survey conducted between 1992 and 1994 in the Ashanti, Brong Ahafo, Eastern and Western Regions of Ghana revealed that the most broadly used pesticides by farmers are: copper(II) hydroxide (29.0\%), mancozeb $(11.0 \%)$, fenitrothion $(6.0 \%)$, dimethoate $(11.0 \%)$, pirimiphos methyl $(11.0 \%), \lambda$-cyhalothrin $(22.0 \%)$, and endosulfan $(10.0 \%)$ [19]. Moreover, it was established that insecticides constituted about $67 \%$ of pesticides employed by farmers while fungicides were about $30 \%$ and herbicides and other pesticides types form $3 \%$ of the total use.

On the other hand, it is on record that between 1995 and 2000, an average of 814 tons of pesticides was imported into the country annually, the greatest quantity being insecticides, $70 \%$ [5]. The amount of pesticides imported into the country from 2002 to 2006 increased 
from 7763 metric tonnes to 27,886 metric tonnes, (Table 3). Updated register of pesticides from the Environmental Protection Agency in Ghana in 2008 indicated that about 141 different types of pesticide products have been registered in the country under the Part II of the Environmental Protection Agency Act, 1994 (Act 490). These consists of insecticides (41.84\%), fungicides (16.31\%), herbicides $(0.43 \%)$ and others $(0.01 \%)$ [20].

\section{Pesticides in Surface and Ground Water}

A fundamental contributor to the "Green Revolution" has been the development and application pesticides for the control of a wide variety of pests that would otherwise diminish the quantity and quality of food produce [2]. Notwithstanding the increased food production, massive use of pesticides has caused serious contamination of aquifers and surface water bodies, decreasing the quality of water for human consumption $[1,21]$. Pesticide residues have been a catch cry of environmental and consumer groups since the mid-1960's when Rachel Carson [22] drew the public's attention to the deleterious ecological effects of organochlorine pesticides especially 1,1,1-trichloro-2,2-bis-(4'-chlorophenyl) ethane (DDT), which were in widespread use at that time.

Water samples from rivers in the intensive cocoa growing areas in the Ashanti and Eastern Regions of Ghana have been found to contain lindane and endosulfan [23]. Water samples from Akumadan, a vegetable farming community in the Ashanti Region and different areas of Ghana revealed the presence of significant levels of pesticide residues (Table 4). The Volta Lake was also found to be mildly contaminated with lindane, DDT, DDE and endosulfan [17]. In Oda, Kowire and Atwetwe rivers in Ghana, mean pesticide concentrations found in water samples for lindane and endosulfan were 19.4 and $12.4 \mu \mathrm{g} \cdot \mathrm{L}^{-1}$ (Oda), 16.4 and $17.9 \mu \mathrm{g} \cdot \mathrm{L}^{-1}$ (Kowire) 20.5 and $21.4 \mu \mathrm{g} \cdot \mathrm{L}^{-1}$ (Atwetwe), respectively [23].

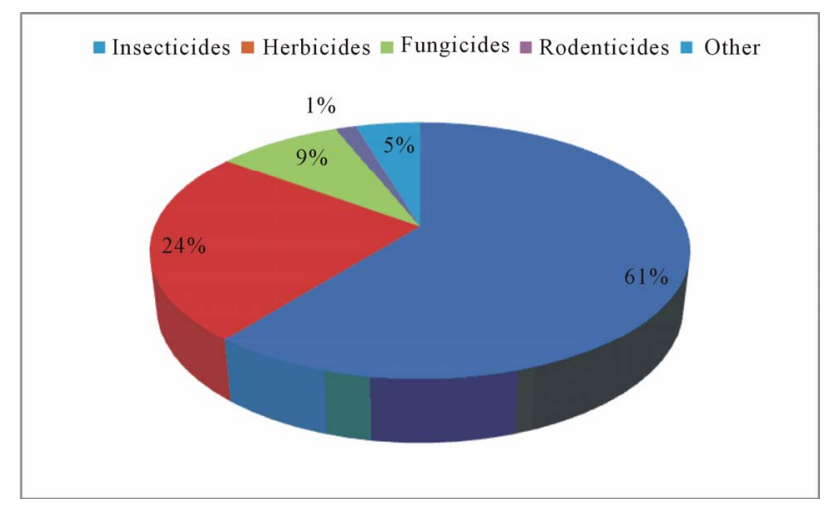

Figure 1. Distribution of pesticides imported into Ghana in 1993.

Table 3. Annual imported pesticides into Ghana from 2002 to 2006.

\begin{tabular}{cccccc}
\hline \multirow{2}{*}{ Class of Pesticide } & \multicolumn{5}{c}{ Metric Tonnes } \\
\cline { 2 - 6 } & 2002 & 2003 & 2004 & 2005 & 2006 \\
\hline Insecticides & 4130 & 5974 & 8418 & 10,006 & 12,728 \\
Herbicides & 2186 & 2939 & 4578 & 8566 & 10718 \\
Fungicides & 1079 & 1249 & 2402 & 2205 & 3195 \\
Others & 368 & 496 & 544 & 707 & 1224 \\
Total & $\mathbf{7 7 6 3}$ & $\mathbf{1 0 , 6 5 8}$ & $\mathbf{1 5 , 9 4 2}$ & $\mathbf{2 1 , 4 8 4}$ & $\mathbf{2 7 , 8 8 6}$ \\
\hline
\end{tabular}

Table 4. Pesticides detected in water samples from different areas of Ghana.

\begin{tabular}{|c|c|c|c|c|}
\hline Area & Detected & Concentration $\left(\mu \mathrm{g} \cdot \mathbf{L}^{-1}\right)$ & Freq. of detection & Reference \\
\hline \multirow{4}{*}{ Akomadan } & Lindane & 9.5 & 76 & \multirow[t]{4}{*}{ [24] } \\
\hline & $\alpha$-endosulfan & 62.3 & 64 & \\
\hline & $\beta$-endosulfan & 31.4 & 60 & \\
\hline & Endosulfan sulfate & 30.8 & 78 & \\
\hline \multirow{6}{*}{ Volta Lake } & Lindane & 0.008 & 22.8 & \multirow[t]{6}{*}{ [17] } \\
\hline & $\alpha$-endosulfan & 0.036 & 15.6 & \\
\hline & $\beta$-endosulfan & 0.024 & 17.8 & \\
\hline & Endosulfan sulfate & 0.023 & 10.6 & \\
\hline & $\mathrm{P}, \mathrm{p}-\mathrm{DDT}$ & & & \\
\hline & $P, p^{\prime}-D D E$ & & & \\
\hline \multirow{4}{*}{ Bosomtwi Lake } & Lindane & 0.071 & & \multirow[t]{4}{*}{ [24] } \\
\hline & Endosulfan & 0.064 & & \\
\hline & DDE & 0.061 & 82 & \\
\hline & DDT & 0.012 & 78 & \\
\hline
\end{tabular}




\section{Pesticides in Food}

Effects of pesticides have been reported in milk, vegetables, fruits, meat, fish meal and other food at different intervals in the country. Analysis of street-vended food samples in Accra, between 1999-2000 revealed disturbing levels of contamination by pesticides, heavy metals, microorganisms and mycotoxins [23]. The pesticide chlorpyrifos was detected in six out of eight samples of waakye (rice and beans) and one out of eight samples of fufu (cassava and plantain dough). Vegetables on the Ghanaian market were found to contain detectable levels of chlopyrifos, lindane, endosulfan, lambda-cyhalothrin, and DDT residues in lettuce, cabbage, tomato and onion $[6,25,26]$.

Significant amount of different pesticides have been reported for other foods besides that in vegetables and fruits (Table 5). The possible reason for pesticides to

Table 5. Pesticide residues in different foods in Ghana.

\begin{tabular}{|c|c|c|c|c|}
\hline Area & Commodity & Detected & Concentration $\left(\mu \mathrm{g} \cdot \mathrm{kg}^{-1}\right)$ & Reference \\
\hline \multirow[t]{11}{*}{ Kumasi abattoir } & Beef fat & Lindane & 4.04 & {$[24]$} \\
\hline & & endosulfan & 21.35 & \\
\hline & & Aldrin & 2.06 & \\
\hline & & DDE & 118.45 & \\
\hline & & DDT & 545.24 & \\
\hline & & dieldrin & 5.25 & \\
\hline & & endosulfan & 1.88 & \\
\hline & & Aldrin & 1.43 & \\
\hline & & DDE & 42.93 & \\
\hline & & DDT & 18.83 & \\
\hline & & dieldrin & 5.92 & \\
\hline \multirow[t]{11}{*}{ Buoho abattoir } & Beef fat & Lindane & 1.79 & \\
\hline & & endosulfan & 2.28 & \\
\hline & & DDE & 31.89 & \\
\hline & & DDT & 403.82 & \\
\hline & & dieldrin & 6.01 & \\
\hline & Beef & Lindane & 0.60 & \\
\hline & & endosulfan & 0.59 & \\
\hline & & Aldrin & 0.73 & \\
\hline & & DDE & 5.86 & \\
\hline & & DDT & 10.82 & \\
\hline & & dieldrin & 11.48 & \\
\hline \multirow[t]{4}{*}{ Kumasi } & Cheese & DDE & 31.50 & \\
\hline & Yoghourt & DDT & 42.17 & \\
\hline & milk & DDT & 12.53 & \\
\hline & & Endosulfan sulfate & 10.6 & \\
\hline \multirow[t]{4}{*}{ Bosomtwi Lake } & fish & Lindane & 0.126 & \\
\hline & & Endosulfan & 0.713 & \\
\hline & & Aldrin & 0.018 & \\
\hline & & dieldrin & 0.035 & \\
\hline \multirow[t]{9}{*}{ Kumasi } & Vegetables & Chlorpyrifos-methyl & 94.0 & \\
\hline & & Chlorpyrifos & 153.5 & \\
\hline & & Dichlorvos & 86.5 & \\
\hline & & Dimethoate & 117.5 & \\
\hline & & Malathion & 209 & \\
\hline & & Monocrotophos & 61.5 & \\
\hline & & Omethioate & 61 & \\
\hline & & Parathion methyl & 31 & \\
\hline & & parathion & 71 & \\
\hline \multirow[t]{5}{*}{ Kumasi } & Lettuce & Lindane & 300 & {$[25]$} \\
\hline & & Lambda Cyhalothrin & 500 & \\
\hline & & DDT & 400 & \\
\hline & & Chlorpyrifos & 1600 & \\
\hline & & Endosulfan & 400 & \\
\hline
\end{tabular}


reach these aquatic environments is through direct runoff, leaching, careless disposal of empty containers, equipment washing etc which is evident from literature [2]. Studies on pesticide residues in exportable quality cocoa beans collected from selected cocoa growing districts in the middle belt of Ghana and the two shipping ports at Tema and Takoradi also showed detectable amount of lindane residues; the average level was about $10 \%$ of the maximum residue level of $0.1 \mu \mathrm{g} / \mathrm{g}$ permitted by Codex Alimentarius Commission [27]. Nonetheless, many other studies conducted so far have revealed the presence of detectable levels of pesticides especially organochlorines in fruits, vegetables, fish and fish products $[12,27,28]$. The studies pointed out that majority of the samples contaminated by chlorinated pesticides exceeded the maximum residue limits which could cause pesticide hazard to the consumer.

\section{Pesticides in Soils and Sediments}

The natural processes that govern that fate and transport of agrochemicals especially pesticides in the environment can be grouped into the broad categories of runoff, leaching, sorption, volatilization, degradation and plant uptake [29]. Once applied to soil, a number of things may happen to an agrochemical [30]. It may be taken up by plants or ingested by animals, insects, worms, or microorganisms in the soil. It may move downward in the soil and either adheres to particles or dissolve. The pesticide may vaporize and enter the atmosphere, degrade via solar energy or break down via microbial and chemical pathways into other less toxic compounds. Pesticides may leach out of the root zone or wash off the surface of land by rain or irrigation water, eventually ending in the sediments through the water column. Evaporation of water at the ground surface can lead to upward flow of water and pesticide [30].

The fate of pesticides applied to soil depends largely on two of its properties: persistence and sorption $[1,2,29]$. Two other pathways of pesticide loss are removal in the harvested plant and volatilization into the atmosphere, which subsequently impact water, sediment, soil, and air quality negatively and creating problems for agricultural workers who could be pesticide intoxicated via inhalation at the treated areas. The sources of all these contamination are the consequences of human activities like domestic, industrial discharges, agricultural chemical application and soil erosion due to deforestation. Accordingly, high concentrations of pesticide residues in harvested produce could have ecological health impacts on consumers. However, in the case of fish subsequent accumulation in biota could occur through bioaccumulation and biomagnifications through different trophic levels in the aquatic food chain.

Studies in Ghana $[17,24,31,32]$ have reported the detection of different kinds of pesticides especially organochlorines in soil and sediment in different parts of Ghana (Table 6). The fate of propoxur residues in cocoa ecosystem studied revealed that no residue of propoxur could be detected after 21 days after spraying [33].

Glover-Amengor et al., [31] and Nuertey et al., [32]

Table 6. Pesticides detected in soils/sediments in Ghana.

\begin{tabular}{|c|c|c|c|c|}
\hline Area & Detected & Concentration $\left(\mu \mathrm{g} \cdot \mathrm{kg}^{-1}\right)$ & Frequency of Detection (\%) & Reference \\
\hline \multirow{7}{*}{ Akomadan (Soil) } & Lindane & 3.20 & 95.2 & [6] \\
\hline & $\alpha$-endosulfan & 0.19 & 95 & \\
\hline & $\beta$-endosulfan & 0.13 & 88 & \\
\hline & Endosulfan Sulfate & 0.23 & 97 & \\
\hline & $\mathrm{HCB}$ & 0.90 & 90.5 & \\
\hline & Heptachlor & 0.63 & 97.6 & \\
\hline & DDE & 0.46 & 88.1 & \\
\hline \multirow{6}{*}{ Volta Lake (Sediment) } & Lindane & 2.30 & 91.7 & [17] \\
\hline & $\alpha$-endosulfan & 0.21 & 86.1 & \\
\hline & $\beta$-endosulfan & 0.17 & 88.9 & \\
\hline & Endosulfan Sulfate & 0.36 & 94.4 & \\
\hline & $\mathrm{P}, \mathrm{p}-\mathrm{DDT}$ & 9.00 & 22.2 & \\
\hline & P,p'-DDE & 52.30 & 97.2 & \\
\hline \multirow{6}{*}{ Bosomtwi Lake (sediment) } & Lindane & 6.76 & & [24] \\
\hline & Endosulfan & 9.68 & & \\
\hline & DDE & 8.34 & 98 & \\
\hline & DDT & 4.41 & & \\
\hline & Aldrin & 0.065 & & \\
\hline & Dieldrin & 0.072 & & \\
\hline
\end{tabular}


measured the effect of excessive use of pesticides on biomass and microorganisms in oil palm and vegetable agro-ecosystems. They observed that the pesticides inhibit bacterial population resulting in inhibited nitrification and blockage of other soil microorganisms of both organic and inorganic constituents in the soil, hence decreasing the soil fertility. Yield of vegetables notably garden eggs and tomato were suppressed by increased application of lindane. Pesticide application had a higher effect on fungal population.

Studies of the solubility of pesticides and its sorption on soil are known to be inversely related, increased solubility implies less sorption. One of the most useful indices for quantifying pesticide sorption on soils is the partition coefficient (Koc) defined as the ratio of pesticide concentration in the sorbed-state (bound to soil particles) to solution-phase (dissolved in the soil-water). Thus, for a given amount of pesticide applied, the smaller the Koc value, the greater the concentration of pesticide in solution. Pesticides with small Koc values are more likely to be leached compared to those with large Koc values [34]. Studies on depletion of herbicides in two soil ecosystems in Ghana [35] indicated that the kinetics involved in the process of depletion of the herbicides to a higher degree could be described as first order reaction kinetics and the half-life of herbicides ranged between 14.8 and 32.2 days. Apoh et al., [36] in their study of the persistence of lindane in Ghanaian coastal savanna topsoil reported that the dissipation pattern favours second order kinetics and persistence depend on the organic matter content of the soil.

Sunlight induced reactions may contribute to the chemical transformation of organic pollutants. Recent evidence $[29,30]$ suggests that organic pollutants may react through both direct and indirect photochemical pathways. Many river basins are eutrophic and contain higher amounts of dissolved organic matter (DOM). In connection with these, studies of both DOM and nitrate was shown to the degradation of pesticides by sunlight. Moisture and organic matter content was found to facilitate depletion of herbicides in soils $[31,35,36]$. The degree to which this could occur may highly depend upon the composition and amount of photosensitizers present. Most of the dissolved organic matter in natural waters is comprised of decomposed organic matter and extracellular products as well as amorphous humic substances which may contain a variety of chromophoric functional groups that absorb sunlight.

\section{Pesticides and Human Health Impacts}

Pesticides have improved longevity and the quality of life, chiefly in the area of public health. The use of pesticides also constitutes an important aspect of modern ag- riculture. Unfortunately, most pesticides are poisons and can be particularly dangerous when misused. Fish-kills, reproductive failure in birds, and acute illnesses in people have all been attributed to exposure to or ingestion of pesticides, usually as a result of misapplication or careless disposal of unused pesticides and containers. Pesticide losses from areas of application and contamination of non-target sites such as surface and ground water represent a monetary loss to the farmer as well as a threat to the environment [1].

Meeting the minimum requirements of occupational health standards is regarded as one of the elements of sustainable agricultural development. In Ghana, there are no countrywide statistics on the extent of poisoning of farmers through pesticide. Three reasons have been identified for this: 1) farmers seek medical attention only in cases of serious health problems due to the costs involved 2) most of the farmers are not aware of the specific symptoms of pesticide poisoning and 3) health workers are not informed and therefore cannot draw the right conclusions, and the system of health statistics does not clearly specify cases of poisoning.

While epidemiological studies have often implicated agrochemicals especially pesticides as causative agents in human cancer, it has usually been at a marginal level of significance. It is suspected that DDT and its metabolite DDE, still persisted in the environment long after being banned and may be involved in the causation of breast cancer as a result of estrogenic activity [16]. Human exposure to pesticides in Ghana may be excessive, especially through ground application in cocoa, pineapple, cotton and vegetable farms where compounds of high toxicity are often used $[33,38]$. Large number of workers, labourers, and spraying observers are involved in spraying of these farms but unfortunately, they are often not equipped with protective clothes or masks. Therefore, this may reflect the great magnitude of human exposure to pesticide intoxication in Ghana. Official reports on agro-chemical poisoning are lacking, except a few published reports $[2,5,8]$. A survey on the extent of pesticide associated symptoms in farmers involved in irrigation projects in Ghana revealed that about $36 \%$ of the farmers had experienced negative side effects after applying pesticides [16]. The most significant symptoms include headache, dizziness, fever, blurred vision, and nausea/vomiting. A study on farmer's perception and use of pesticides in Ghana [8] also revealed that although some farmers may be aware of pesticide hazards, adequate protection is hardly taken to minimize risk while knowledge of pesticide selection, application rates and timing are also poor.

A study on possible poisoning caused by pesticides was carried out by researchers of the Ghana Standards Board 
and the Department of Pathology of the University of Ghana between 1989 and 1997 [37]. The research analyzed organs of the body, body fluids, foods and drinks submitted by various hospitals and other state institutions in Ghana. Out of the 1215 toxicological cases examined, 963 tested positive for chemical poisoning. The 30\% cases of chemical poisoning were directly related to the misuse of pesticides. The main causes for deaths were carbamates (126 cases), organophosphorous (66 cases) and organochlorines (74 cases). Unfortunately in March 1999, three children died after consuming fruits containing high residue of carbamates [5] in Ghana.

An epidemiological survey and haematological studies on the probable effect of pesticide on the health status of farmers in Akomadan and Afrancho traditional area of the Ashanti Region of Ghana conducted by Mensah et al. [38], revealed that most of the farmers have experienced sneezing (56\%), skin irritation (65.9\%), headaches (48.2\%), dizziness $(40.0 \%)$, abdominal pains $(20.0 \%)$ and cough $(57.6 \%)$. About $30 \%$ of the farmers were found to have low red blood cells (RBC) and 38\% low white blood cells (WBC). Yeboah et al., [39] reported cases of fatal occupational poisoning recorded by the Plant Protection and Regulatory Services of the ministry of Agriculture in Ghana (PPRS) between 1986 and 1989.

Further investigation into probable effects of aerosol pesticides on hepatic functions among farmers in Akomadan and Afrancho districts in the Ashanti region [12] indicated that aerosol pesticides used by farmers did not pose any immediate threat to hepatic function of farmers at least in short term, however, long term effect of persistent pesticide usage could not be overlooked. Mercury from mercuric pesticide has been known to cause poisonings in areas where seed grains were treated with mercuric pesticides to curb fungal growth. These occurrences have exhibited toxic effects in humans and wildlife [40] in Ghana. Feeding birds are also susceptible to adverse effects of mercuric pesticide coated grains and several species have experienced reduced reproduction and increased mortality. Thus, the unfortunate consequences of pesticide use has led to wildlife distress, interference with reproduction, birth defects, and depressed immunity which detrimentally affects wildlife populations and on a larger scale the surrounding ecosystem.

\section{Pesticides in Air and Human Exposure}

In Ghana, the chances of misuse of agrochemicals are relatively high due to low awareness of the safe use of agrochemicals especially pesticides and illiteracy. There are various means by which human become exposed to agrochemicals and other toxic chemicals, notable among which are exposure via diet, drinking water, soil and air. Persistent pesticides move through air, soil, and water finding their way into living tissues where they can bioaccumulate up the food chain. The public health risks of pesticides depend not only on how toxic various compounds are, but also on how many people are exposed, their risk-related demographic, socioeconomic and health profile, the kinds of contaminants they are exposed to, and the extent and routes of exposure. The general population can be exposed to low levels of pesticides in three general ways: vector control for public health and other non-agricultural purposes; environmental residues; and food residues.

Health and safety issues are exacerbated by a general lack of hazard awareness; the lack of protective clothing, or difficulty of wearing protective clothing in tropical climates; shortage of facilities for washing after use, or in case of accidents; the value of containers for re-use in storing food and drink; illiteracy; labeling difficulties relating either to language, complexity or misleading information; lack of regulatory authorities; and lack of enforcement. Poisoning surveillance systems are usually maintained only at large urban hospitals. Village health centers may be completely excluded from monitoring reports [16].

A study by Yeboah et al., [12] and Mensah et al., [38], revealed that about $82 \%$ of farmers in Ghana are illiterates and do not always use any form of standard protective clothing. Most of the farmers were not aware of long term chemical and physiological effect associated with improper agrochemical handling. About $41.5 \%$ of farmers claim they change their cloths before and after pesticide use, however, less than 5\% washed these clothing before using them again. These contaminated clothing can enhance dermal exposure which can result in systemic poisoning. It was also revealed that some of the farmers were involved in unhealthy practices that put them at high risk of being affected by the pesticides. They drink from water bodies near their farms and eat without washing their hand with any detergent.

Malnutrition could bring about an increased susceptibility to pesticide intoxication, especially in women and children. Malnourishment, infectious diseases, and toxic chemicals interact with each other and with the immune system. Consequently, pesticides immunosuppressive effects which have more pronounced health consequences in developing countries, could significantly affect immune responses at very low doses. Humans ingesting food preparations contaminated with pesticide, workers in pesticide manufacturing and packing units, and agricultural workers who prepare, mix, and apply pesticides in the fields are all potentially exposed to more than one pesticide on the same or on successive days. Such exposure may induce a wide array of health effect, ranging from myelotoxicity to cytogenetic changes and carcino- 
genic effects.

Human exposure is on more sporadic basis through a hodgepodge of human activities, farmers and farm workers; workers and laborers in pesticide factories; populations that live in areas of intensive pesticide use or production; and populations exposed to persistent pesticides that bioaccumulate in food are potentially exposed to pesticide hazards [12]. Those that can be exposed to high levels of bio-accumulated pesticides include: consumers of fish, livestock, and dairy products; foetus and nursing infants whose mother's bodies have accumulated substantial levels of persistent agrochemicals; and sick people who metabolize pesticide-bioaccumulated fatty tissues while ill [38]. Soil can be a key source of exposure in young children who show significant hand-tomouth activity. Although modern pesticides are readily degraded in the environment by soil micro-organisms, residues on treated crops such as fruit or vegetables often do not dissipate quickly. Most pesticides lack systemic action and therefore residues are mainly on the exterior surfaces where they are amenable to removal in operations such as trimming, washing or peeling that most crops undergo before consumption.

\section{Conclusions}

Agrochemicals are generally recognized as a significant factor in enhancing the ability to meet Ghana's need for sufficient, safe and affordable food and fiber, however, increased usage have led to environmental deterioration. The review of agrochemical monitoring and exposure clearly indicate that not much have been done in the area of agrochemical studies in Ghana. There was lack or absence of corrective and preventive measures, presence of persistent, bioaccumulative and toxic agrochemicals in water, fish, vegetables and human fluids and there is strong evidence that accidents of pesticide exposure in Ghana may occur due to lack of awareness about safe use of agrochemicals. Keeping in view of the present scenario, it is strongly recommended that extensive awareness creation for safe use of agrochemicals be introduced, epidemiological studies and impact of agrochemical usage in the country be instituted. This will provide information on biological indices of agrochemicals for effective monitoring of exposure of farmers and farm workers to agrochemicals.

\section{REFERENCES}

[1] P. F. Carvalho, "Agriculture, Pesticides, Food Security and Food Safety," Environmental Science and Policy, Vol. 9, No. 7-8, 2006, pp. 685-692. doi:10.1016/j.envsci.2006.08.002

[2] M. I. Tariq, S. Afzal, I. Hussain and N. Sultana, "Pesti- cide Exposure in Pakistan: A Review," Environment International, Vol. 33, No. 8, 2007, pp. 1107-1122. doi:10.1016/j.envint.2007.07.012

[3] FAO, "Fertilizer Use by Crop in Ghana," FAO Corporate Document Repository, Rome, 2005.

[4] Ministry of Food and Agriculture (MOFA), "Agriculture in Ghana: Facts and Figures," Produced by the Statistics, Research and Information Directorate, Accra, 2003.

[5] FAO, "Scaling soil nutrient balances," FAO Fertilizer \& Plant Nutrition Bulletin, No. 15, Rome, 2004.

[6] W. J. Ntow, "Organochlorine Pesticides in Water, Sediment, Crops and Human Fluids in a Farming Community in Ghana," Environmental Contamination and Toxicology, Vol. 40, No. 4, 2001, pp. 557-563. doi: $10.1007 / \mathrm{s} 002440010210$

[7] Ministry of Food and Agriculture (MOFA), "National Soil Fertility Management Action Plan," Directorate of Crop Services, Accra, Ghana, 1998.

[8] J. W. Ntow, H. J. Gijzen, P. Kelderman and P. Drechsel, "Farmer Perception and Pesticide Use Practices in Vegetable Production in Ghana," Pest Management Science, Vol. 62, No. 4, 2006, pp. 356-365.

doi:10.1002/ps. 1178

[9] M. Kyofa-Boamah and E. Blay, "A Study on Pineapple Production and Protection Procedure in Ghana," Ministry of Food and Agriculture, Plant Protection and Regulatory Services Directorate, Accra, Ghana, 2000.

[10] A. R. Cudjoe, M. Kyofa-Boamah and M. Braun, "Selected Fruit Crops (Mango, Papaya and Pineapple)," Handbook of Crop Protection Recommended in Ghana, an IPM Approach, Ministry of Food and Agriculture/Plant Protection and Regulatory Services Directorate/GTZ, Accra-Ghana, Vol. 4, 2002, pp. 60-63.

[11] E. Aboagye, "Patterns of Pesticide Use and Residue Levels in Exportable Pineapple (Ananas Cosmosus L. Merr)," M.Phil Thesis, University of Ghana, Legon, 2002.

[12] F. A. Yeboah, F. O. Mensah and A. K. Afreh, "The Probable Toxic Effects of Aerosol Pesticides on Hepatic Function among Farmers at Akomadan/Afrancho Traditional Area of Ghana," Journal of Ghana Science Association, Vol. 6, No. 2, 2004, pp. 39-43.

[13] B. Dinham, "Growing Vegetables in Developing Countries for Local Urban Populations and Export Markets: Problems Confronting Small-Scale Producers," Pest Management Science, Vol. 59, No. 5, 1993, pp. 575-582. doi:10.1002/ps.654

[14] B. Awumbila and E. Bokuma, "Survey of Pesticides Used in the Control of Ectoparasites of Farm Animals in Ghana," Tropical Animal Health and Production, Vol. 26, No. 1, 1994, pp. 7-12. doi:10.1007/BF02241125

[15] B. Awumbila, "Acaricides in Tick Control in Ghana and Methods of Application," Tropical Animal Health and Production, Vol. 28, No. 2, 1996, pp. 10-16. doi:10.1007/BF02310699

[16] E. E. K. Clarke, L. S. Levy, A. Spurgeon and I. A. Calvert, "The Problems Associated with Pesticide Use by Ir- 
rigation Workers in Ghana," Occupational Medicine, Vol. 47, No. 5, 1997, pp. 301-308.

doi:10.1093/occmed/47.5.301

[17] J. W. Ntow, "Pesticide Residues in Volta Lake, Ghana," Lakes and Reservoirs: Research and Management, Vol. 10, No. 4, 2005, pp. 243-248. doi:10.1111/j.1440-1770.2005.00278.x

[18] O. Boateng, "External Trade Statistics January-December 1992," Ghana Statistical Services, Accra, 1993, pp. 79-80.

[19] S. O. Acquaah and E. Frempong, "Organochlorine Insecticides in African Agrosystem," IAEA, IAEA TECDOG-93, Vienna, 1995, pp. 111-118.

[20] Ghana, EPA, "Registered Pesticides Handbook," Ghana Environmental Protection Agency, Accra, 2008.

[21] J. A. Camargo and A. Alonso, "Ecological and Toxicological Effects of Inorganic Nitrogen Pollution in Aquatic Ecosystems: A Global Assessment," Environment International, Vol. 32, No. 6, 2006, pp. 831-849. doi:10.1016/j.envint.2006.05.002

[22] R. Carson, "Silent Spring," Fawcett Crest, Greenwich, 1962.

[23] S. O. Acquaah, "Lindane and Endosulfan Residues in Water and Fish in the Ashanti Region of Ghana," Proceedigs of Symposium on Environmental Behaviour of Crop Protection Chemicals by the IAEA/FAO, IAEA, Vienna, 1-5 July, 1997.

[24] G. Darko and S. O. Acquaah, "Levels of Organochlorine Pesticide Residues in Diary Products in Kumasi, Ghana," Chemosphere, Vol. 71, No. 2, 2008, pp. 294-298. doi:10.1016/j.chemosphere.2007.09.005

[25] A. K. Armah, G. A. Dapaah and G. Wiafi, "Water Quality Studies on Two Irrigation Associated Rivers in Southern Ghana," Journal of Ghana Science Association, Vol. 1, No. 2, 1999, pp. 100-109.

[26] W. J. Ntow, "Pesticide Misuse at Akumadan to be Tackled," NARP Newsletter, Vol. 3, No. 3, 1998.

[27] F. Botchway, "Analysis of Pesticide Residues in Ghana's Exportable Cocoa," Higher Certificate Project, Institute of Science and Technology, London, 2000.

[28] D. K. Essumang, G. K. Togoh and L. Chokky, "Pesticide Residues in the Water and Fish (Lagoon Tilapia) Samples from Lagoons in Ghana," Bulletin of the Chemical Society of Ethiopia, Vol. 23, No. 1, 2009, pp. 19-27.

[29] L. R. Goldman and S. Koduru, "Chemicals in the Environment and Developmental Toxicity to Children: A Public Health Policy Perspective," Environmental Health Perspectives, Vol. 109, No. 9, 2001, pp. 412-413.
[30] D. C. Gooddy, P. J. Chilton and I. Harrison, "A Field Study to Assess the Degradation and Transport of Diuron and Its Metabolites in a Calcareous Soil," Science of the Total Environment, Vol. 297, No. 1-3, 2002, pp. 67-83. doi:10.1016/S0048-9697(02)00079-7

[31] M. Glover-Amengor and F. M. Tetteh, "Effects of Pesticide Application Rate on Yield of Vegetables and Soil Microbial Communities," West Africa Journal of Applied Ecology, Vol. 12, 2008, pp. 1-7.

[32] B. N. Nuertey, F. M. Tetteh, A. Opoku, P. A. Afari and T. E. O. Asamoah, "Effect of Roundup-Salt Mixtures on Weed Control and Soil Microbial Biomass under Oil Palm Plantation," Journal of Ghana Science Association, Vol. 9, 2007, pp. 61-75.

[33] P. O. Yeboah, S. Lowor and C. K. Akpabli, "Comparism of Thin Layer Chromatography and Gas Chromatography Determination of Propoxur Residues in a Cocoa Ecosystem," African Journal of Science and Technology, Vol. 4, No. 2, 2003, pp. 24-28.

[34] W. J. Mavura and P. T. Wangila, "Distribution of Pesticide Residues in Various Lake Matrices: Water, Sediment, Fish and Algae, the Case of Lake Nakuru, Kenya," ANCP Inaugural Conference Proceedings, Tanzania, 2004.

[35] S. Afful, S. A. Dogbe, K. Ahmad and A. T. Ewusie, "Thin Layer Chromatographic Analyses of Pesticides in a Soil Ecosystem," West Africa Journal of Applied Ecology, Vol. 14, 2008, pp. 1-7.

[36] F. E. Apoh, P. O. Yeboah and D. K. Dodoo, "Persistence of Lindane in Ghanaian Coastal Savanna Topsoil," Proceedings of the 6th International Chemistry Conference in Africa, University of Ghana, Legon, 1995.

[37] E. Adetola, J. K. Ataki, E. Atidepe, D. K. Osei and A. B. Akosa, "Pesticide Poisoning-A Nine Year Study (19891997)," Department of Pathology, University of Ghana Medical School and Ghana Standards Board, Accra, 1999.

[38] F. O. Mensah, F. A. Yeboah and M. Akman, "Survey of the Effect of Aerosol Pesticide Usage on the Health of Farmers in the Akomadan and Afrancho Farming Community," Journal of Ghana Science Association, Vol. 6, No. 2, 2004, pp. 44-48.

[39] P. O. Yeboah, G. M. S. Klufio, G. A. Dixon and A. Youdeowe, "TCDC Oriented Subregional Workshop on Pesticides Management Report,” FAO, 1989.

[40] L. K. A. Derban, "Outbreak of Food Poisoning Due to Alkyl Mercury Fungicide on Southern Ghana State Farms," Archives of Environment Health, Vol. 28, No. 1, 1974, pp. 49-52. 